\title{
Optimization high vortex finder of cyclone separator with computational fluids dynamics simulation
}

\author{
Caturwati Ni Ketut, Dwinanto, Attegar \\ Mechanical Engineering Department, University of Sultan Ageng Tirtayasa, 42435 Cilegon - Banten, Indonesia
}

\begin{abstract}
Cyclone separator is an equipment that separates particles contained in the fluid without using filters. The dust particles in the flue gases can be separated by utilizing centrifugal forces and different densities of particles, so that the exhaust gases to be cleaner before discharged into the environment. In this paper carried out a simulation by Computational of Fluids Dynamics to determine the number of particles that can be separated in several cyclone separator which has a ratio body diameter against vortex finder high varied as : $1: 0.5 ; 1: 0.75 ; 1: 1 ; 1: 1.25$ and $1: 1.5$. Fluid inlet are air with antrachite impurity particles that are commonly found in the exhaust gases from tire manufacturers with inlet velocities varied as: $15 \mathrm{~m} / \mathrm{s}$ and 30 $\mathrm{m} / \mathrm{s}$. The results of simulation show the fluids with $15 \mathrm{~m} / \mathrm{s}$ of inlet velocity is generate particle separation value is higher than the fluids with $30 \mathrm{~m} / \mathrm{s}$ inlet velocity for ratio of body diameter and height vortex finder a: 1:0.5 and 1:1.5. For both of inlet velocities the best ratio of body diameter and height vortex finder is $1: 1.25$, where it has the highest values of percentage trapped particles about $86 \%$ for $30 \mathrm{~m} / \mathrm{s}$ input velocity and also for $15 \mathrm{~m} / \mathrm{s}$ input velocity.
\end{abstract}

\section{Introduction}

Cyclone separator is a device for separate solid or liquid particles from carrier gases by centrifugal force wich exists in a stationnaries mechanical device. Cyclones separators are the most widely used for air pollution reducted devices in industries or agricultural processing, without the use of filters The cyclone separator is a highly effective and strong equipment due to the absence of moving parts, so that it can be operated in any environments. The efficiency of separator systems is determined by the size of particles to be separated and the velocity of flow entering devices. [1].

The cyclone separators advantages compared with the other devices, are :

- Capital investment and maintenance cost is low.

- No moving parts.

- Very strong.

- The particles are separated remains dry and can be used again.

- Very compact to be operated.

- Can be formed from a variety of materials needed or suitable such as : casting metals, plate steel, aluminium, alloys, ceramics, plastics, etc.

- Can be equipped with coating material to resist corrosion and erosion such as Teflon.

- With appropriate design can separate either liquid particulates, solid particulates or even both in combination.

Besides the favorable things that there are some things less well among :
- Fluid through cyclone separator has higher pressure loss than the other separator such as scrubber or bag filters.

- Low efficiency values for very small particulate size when operated under small amount particle in the fluids.

- Subject to fouling for the sticky particulate and to erosive wear if particulates being processed are abrassive.

- If the cyclone designed and operated are not properly then product is below expectations.

Figure 1. shows a schematic of a cyclone separator. The tangential inlet gas flow enters cyclone separator at near the top, which gives rise to an axially descending spiral of gas and a centrifugal force field that causes the incoming particles to concentrate along the inner walls of the cyclone separator, and spiral down. Denser or larger size of particles in the rotating stream have big inertia to follow the tight curve of the stream then it strike the outside wall, fall to the bottom of the cyclone where they can be colected. The rotational radius of the stream is reduced in a conical system, so the rotating flow moves towards the narrow end of the cyclone, thus separating smaller and smaller particles

The maximum collection efficiencies is quantified by W.B.Faulkner and B.W.Shaw for the inlet velocities obtained for 1D3D (cylindrical section height $=1 \mathrm{x}$ body diameter ; conical section height $=3$ body diameter ) and 2D2D (cylindrical section height $=2 \times$ body diameter ; conical section height $=2$ body diameter ) cyclones and demonstrated that for large particles,

\footnotetext{
* Corresponding author: n4wati@untirta.ac.id
} 


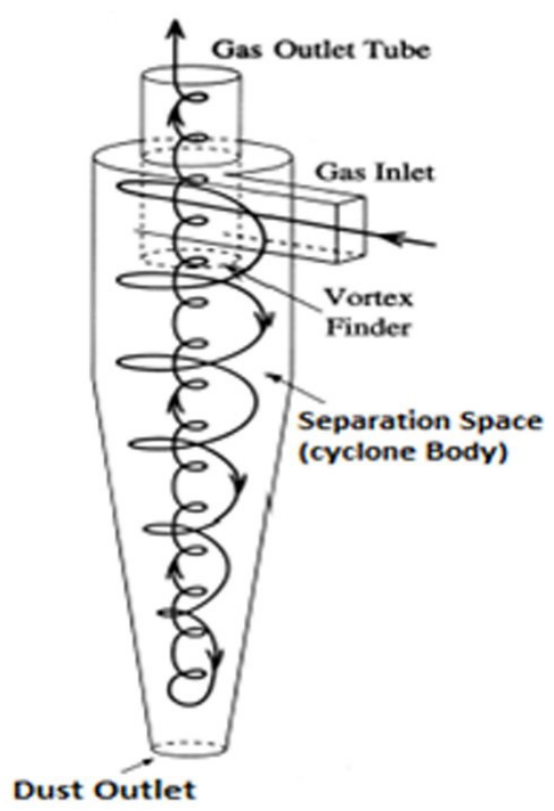

Fig. 1. Schematic of a cyclone separator

the collection efficiency is similar for inlet velocities from $10.16 \mathrm{~m} / \mathrm{s}$ up to the design velocity of six inch diameter 1D3D and 2D2D cyclones [2]. While they have been considered low values efficiency colectors. Recent studies have shown that cyclones efficiencies can reach exceeding $99 \%$ for particle size larger than $5 \mu \mathrm{m}$.[3].

By experimental 1D3D and 2D2D cyclones also evaluated for effect of standard air density on cyclone performance, The results indicate that optimal cyclone design velocities for 1D3D cyclones is $16 \mathrm{~m} / \mathrm{s}$ and for 2D2D cyclones is $15 \mathrm{~m} / \mathrm{s}$ [4].

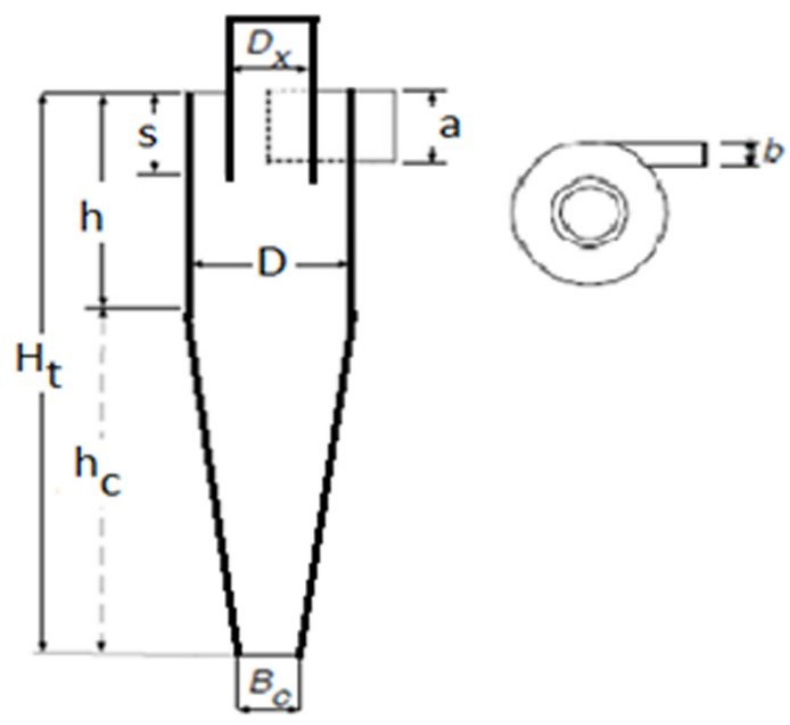

Fig. 2. Geometrical notation of a cyclone separator.

The geometrical notation is indicated in Figure 2. Where :

$\mathrm{D}:$ body diameter

$\mathrm{H}_{\mathrm{t}}$ : total height of the cyclone

$\mathrm{D}_{\mathrm{x}}$ : vortex finder diameter

$\mathrm{S}$ : vortex finder length

a : inlet height $\mathrm{b}$ : inlet width

$\mathrm{h}_{\mathrm{c}}$ : conical section height.

$\mathrm{h}$ : cylindrical/barrel section height.

B: cone-tip diameter

The performance of cyclone separator and flow field pattern has been investigated by computational for the effect of cyclone height. Increasing the cyclone height cause decrease values of maximum tangential velocity, increasing the cone height cause considerably change in axial velocity, and increasing the barrel height makes the axial velocity change small. The changes in the performance at constant cone height for beyond $\mathrm{h} / \mathrm{D}=$ 1.8 are small, whereas the performance at constant barrel height improvement stops after $\mathrm{h}_{\mathrm{c}} / \mathrm{D}=4.0\left(\mathrm{H}_{\mathrm{t}} / \mathrm{D}=\right.$ 5.5).[5]

Type of a cone-shaped cyclone separator with a slot type fluid inlet and reverse flow fluids is a most popular cyclone. Some of relevant literature show simulation results theoretically, experimental and even simulation by computational fluid dynamics (CFD to determine the performance of the cyclone with a slot type inlet for the influence of the geometry and operating conditions. This study also used to develop the design parameters in order to improve the effectiveness of particulate collected or effectiveness of separation. For all types of cyclones separators show general performance of the cyclone separator is determined based on the type and amount of solid particles in fluids inlet. [6], [7], [8], [9].

Another experiment showed an increase effectiveness of particulate collection by adding coarse particles in the cyclone with the coarse particles carrying fine particles move toward the cyclone wall region and down to collector. [10],[11],[12].

The principles of cyclone separator is dust-containing gas is circulation moving around so that the dust particles bounced to the outside wall of cyclone body and then the particles move down to collected.

Swirling flows types can be distinguished of :

1. Free vortex flow : fluid move swirly without friction so that the tangential velocity in the vortex has a value such that a uniform momment of momentum at the same radii.

2. Forced vortex flow : fluid move swirly with friction fluids so that the values of tangential velocity as same a rotating body.

Actual swirling flows has behavior between the two types of swirling flows. For liquids which have an infinitive viscousity (as solid materials) so no sliding motion between the liquid layer. So all liquids at different positions has uniform angular velocity, $\mathrm{V}_{\theta}$, which equals to the tangential velocity, $\mathrm{V}_{\tau}$, devide to radii,r. So for solid body rotation or forced vortex flow, tangential velocity can be expressed as :

$$
V_{\tau}=V_{\theta} \cdot r
$$

In the other words, the movement of fluid element in the swirling fluid without viscosity, the movement of each element is not influenced by neighboring elements where are in the radius of the greater or the radius of the smaller. While the values of the tangential velocity 
increases to radii smaller to maintain constant value of the moment of momentum.

For frictionless vortex, multiple of tangential velocity and radii is constant, $\mathrm{V}_{\tau} \cdot \mathrm{r}=\mathrm{C}$, where $\mathrm{C}$ is a constan number, so that :

$$
V_{\tau}=\frac{C}{r}
$$

An actual Swirling flow generally has a loss- free rotation which area is near the center of solid-body rotation.

The theory for increased of cyclone separators characteristics have been studied by many researchers but no has studies found the influence of vortex finder length dimensions. Therefore, in this paper studied about ratio of body diameter comparison to vortex finder heights in relation to increased efficiency of cyclone separator.

\section{Experimental details}

This study conducted a simulation by a computational fluids dynamics software with geometric parameters of cyclone separator are given in Table 1.

Table 1. Geometric Parameters

\begin{tabular}{|l|l|c|c|}
\hline No. & \multicolumn{1}{|c|}{ Parameter } & Symbol & Dimension (mm) \\
\hline 1. & Body Diameter & $\mathrm{D}$ & 1000 \\
\hline 2. & Inlet height & $\mathrm{a}$ & 500 \\
\hline 3. & Inlet width & $\mathrm{b}$ & 200 \\
\hline 4. & $\begin{array}{l}\text { Vortex finder } \\
\text { diameter }\end{array}$ & $\mathrm{Dx}$ & 500 \\
\hline 5. & Vortex Finder length & $\mathrm{S}$ & varies \\
\hline 6. & $\begin{array}{l}\text { Cylindrical section } \\
\text { height }\end{array}$ & $\mathrm{h}$ & 1500 \\
\hline 7. & Conical section height & $\mathrm{hc}$ & 2500 \\
\hline 8. & Cone tip diameter & $\mathrm{B}$ & 400 \\
\hline
\end{tabular}

The size of vortex finder length is varied from 500 $\mathrm{mm}, 750 \mathrm{~mm}, 1000 \mathrm{~mm}, 1250 \mathrm{~mm}$ to $1500 \mathrm{~mm}$ to make ratio of body diameter against vortex finder heights varied as : $1: 0.5,1: 0.75,1: 1,1: 1.25$ and 1 $: 1.5$.

So we have some type of cyclone separator to make the simulation as :

Type a : vortex finder length $\mathrm{S}=500 \mathrm{~mm}$

Type $b$ : vortex finder length $S=750 \mathrm{~mm}$

Type $\mathrm{c}$ : vortex finder length $\mathrm{S}=1000 \mathrm{~mm}$

Type $\mathrm{d}$ : vortex finder length $\mathrm{S}=1250 \mathrm{~mm}$

Type e : vortex finder length $\mathrm{S}=1500 \mathrm{~mm}$

Figure 3 shows the model geometry of each type of cyclone separator.
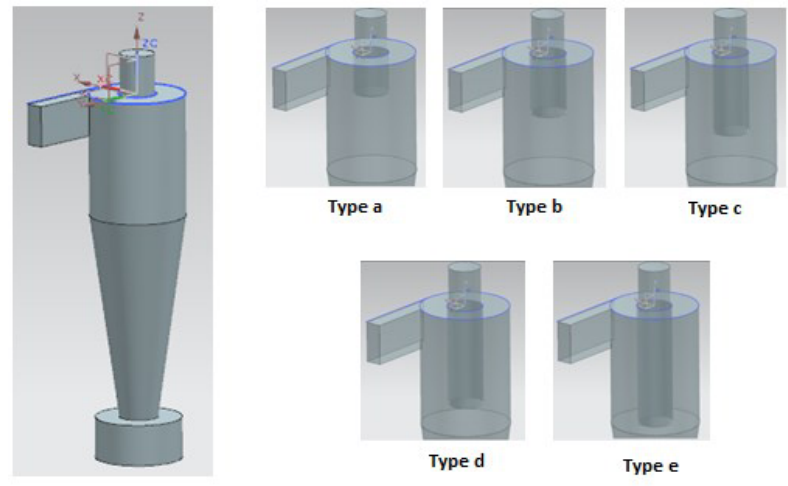

Fig. 3. Model geometry of each type of cyclone separator

Conditions and boundary conditions for make simulation by CFD's are :

Meshing size is $10 \mathrm{~mm}$.

Fluids is air with density : $1.125 \mathrm{~kg} / \mathrm{m}^{3}$ and viscosity : $1.7894 \times 10^{-5} \mathrm{~kg} / \mathrm{m} . \mathrm{s}$

Impurities particle is anthracite with density 1,550 $\mathrm{kg} / \mathrm{m}^{3}$.

Inlet velocity are : $15 \mathrm{~m} / \mathrm{s}$ and $30 \mathrm{~m} / \mathrm{s}$

\section{Results}

The simulation result show maximum pressure in the cyclone separator for velocities inlet $15 \mathrm{~m} / \mathrm{s}$ and $30 \mathrm{~m} / \mathrm{s}$ as showed at Table II and Figure 4. Maximum pressure in cyclone separator as increased as velocities inlet and vortex finder length, $\mathrm{S}$.

Table 2. Maximum Pressure

\begin{tabular}{|c|c|c|}
\hline \multirow{2}{*}{ Ratio S/D } & \multicolumn{2}{|c|}{$\mathbf{P}_{\max }(\mathbf{P a})$} \\
\cline { 2 - 3 } & $\mathbf{V}_{\text {in }}=\mathbf{1 5} \mathbf{~ m} / \mathbf{s}$ & $\mathbf{V}_{\text {in }}=\mathbf{3 0} \mathbf{~ m} / \mathbf{s}$ \\
\hline 0,50 & 424,58 & 1697,11 \\
\hline 0,75 & 428,95 & 1715,74 \\
\hline 1,00 & 437,56 & 1747,97 \\
\hline 1,25 & 450,40 & 1802,54 \\
\hline 1,50 & 462,31 & 1854,84 \\
\hline
\end{tabular}

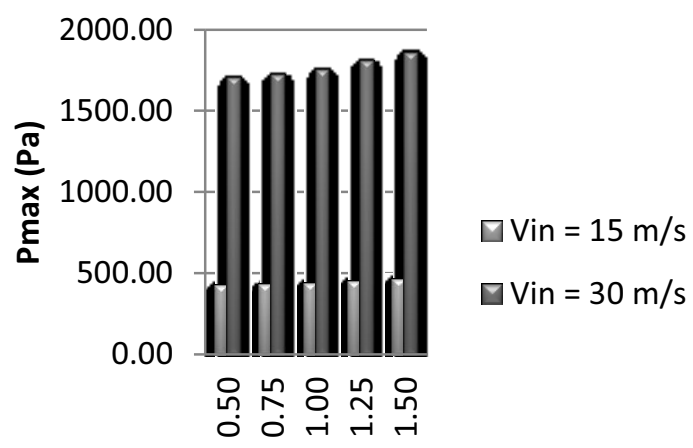

ratio S:D

Fig. 4. Maximum pressure in cyclone separator. 
The maximum velocity in cyclone separator generated from simulation are shown in Table III and Figure 5. Special conditions happen to the value vortex finder length (s) equal to body diameter (D) which has a minimum value for the maximum speed of the fluid in cyclone separator.

Table 3. Maximum Velocity

\begin{tabular}{|c|c|c|}
\hline \multirow{2}{*}{ Ratio S/D } & \multicolumn{2}{|c|}{$\mathbf{V}_{\mathbf{m a x}}(\mathbf{m} / \mathbf{s})$} \\
\cline { 2 - 3 } & $\mathbf{V}_{\text {in }}=\mathbf{1 5} \mathbf{~ m} / \mathbf{s}$ & $\mathbf{V}_{\text {in }}=\mathbf{3 0} \mathbf{~ m} / \mathbf{s}$ \\
\hline 0,50 & 18,97 & 38,07 \\
\hline 0,75 & 19,12 & 38,41 \\
\hline 1,00 & 18,90 & 37,94 \\
\hline 1,25 & 19,03 & 38,22 \\
\hline 1,50 & 19,41 & 38,88 \\
\hline
\end{tabular}

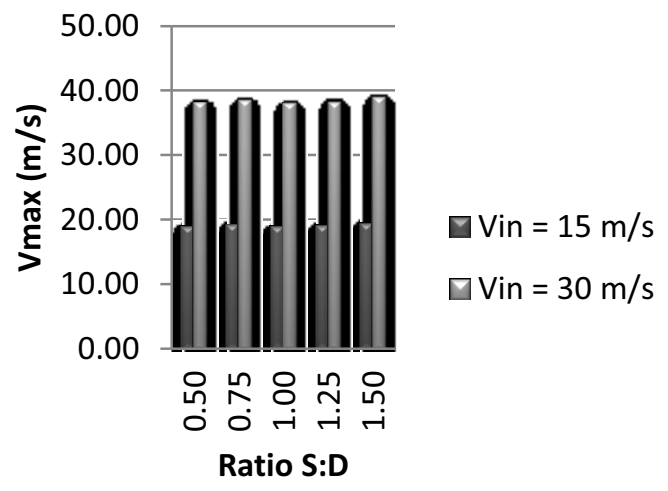

Fig. 5. Maximum velocity in cyclone separator

Besides values of maximum pressure and maximum velocity resulted from the simulation, the most important thing to consider is the separated effectiveness of particles. Which is presented by precentation of traped particles. Table 4. and Figure 6 shows the precentation of traped particles.

Table 4. Percentation Of Trapped Particles

\begin{tabular}{|c|c|c|}
\hline \multirow{2}{*}{ Ratio S/D } & \multicolumn{2}{|c|}{ Traped Particles (\%) } \\
\cline { 2 - 3 } & $\mathbf{V}_{\text {in }}=\mathbf{1 5} \mathbf{~ m} / \mathbf{s}$ & $\mathbf{V}_{\text {in }}=\mathbf{3 0} \mathbf{~ m} / \mathbf{s}$ \\
\hline 0,50 & 82,14 & 78,73 \\
\hline 0,75 & 81,24 & 83,39 \\
\hline 1,00 & 80,55 & 83,51 \\
\hline 1,25 & 85,71 & 85,95 \\
\hline 1,50 & 86,50 & 84,58 \\
\hline
\end{tabular}

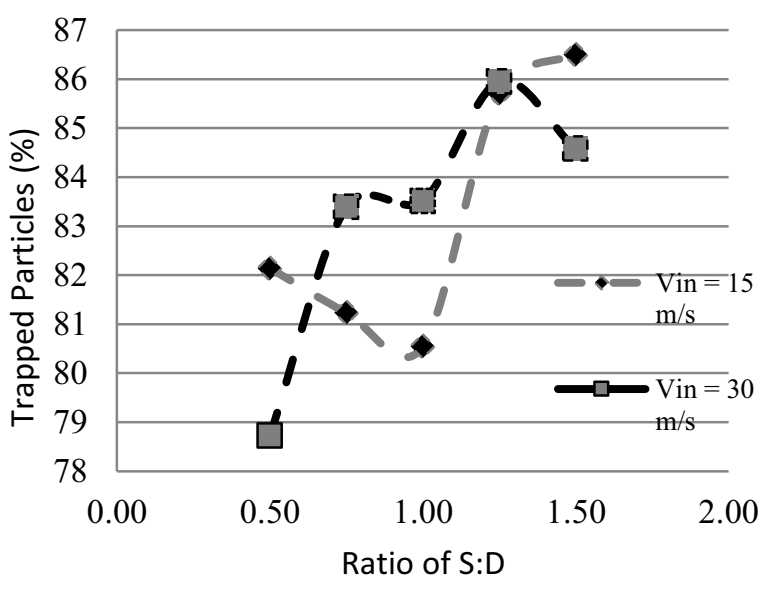

Fig. 6. Percentage of trapped particles

The simulation results for the fluids with velocity input greater $(30 \mathrm{~m} / \mathrm{s})$ has maximum value of trapped particles are in the vortex finder length is $1250 \mathrm{~mm}$. Contrary to the fluid with lower velocity input $(15 \mathrm{~m} / \mathrm{s})$ has a percentage trapped value as length as vortex finder.

\section{Conclusions}

Five cyclones with different vortex finder length have been simulated by computational fluids dynamics methods. Each cyclone imposed on two input values fluid velocity of $15 \mathrm{~m} / \mathrm{s}$ and $30 \mathrm{~m} / \mathrm{s}$. The simulation results are maximum pressure in cyclone separator as increased as velocities inlet and vortex finder length.

Besides that the simulation results show the cyclone separator with vortex finder length is equal with body diameter $(\mathrm{S}=\mathrm{D})$ has the lowest value of the maximum fluid velocity.

The effectiveness of particle separation for input flow rate of $30 \mathrm{~m} / \mathrm{s}$ occur in the value of $\mathrm{S} / \mathrm{D}=1.25$. As for the input flow rate of $15 \mathrm{~m} / \mathrm{s}$ the value effectiveness of particle separation occur in the value of S/D greatest. Conclusions from the simulation results show cyclone separator by $\mathrm{S} / \mathrm{D}$ is equal to 1.25 provides the best value as a particle separator compared to the others.

\section{References}

1. Wang, L.,C.B.Parnell, and B.W. Shaw. Proc. Of the 2000 Beltwide Cotton Conferences. San Antonio, Tex.: National cotton Council (2000).

2. W.B.Faulkner and B.W.Shaw, Applied Engineering in Agriculture Vol. 22(1) : 155-161American Society of Agricultural and Biological Engineers ISSN 0883-8542 ( 2006)

3. Cooper, C.D., and F.C. Alley, A Design Approach, 3rd ed. Prospect Heights, III, Waveland 2002.

4. LingJuan Wang, Texas A\&M University (2004)

5. Khairy Elsayed, Department of Mechanical Engineering, Vrije Universiteit Brussel, (2011)

6. A.C. Hoffmann and L.E.Stern, Gas Cyclones and Swirl Tubes, Springer (2002) 
7. G.B. Sakura, Andrew Y.T.Leung, International Journal of Environmental Science and Development, Vol. 6, No. 3 March (2015)

8. W. Barth, Brennstoff-Warme-Kraft, vol. 8 (1956)

9. C.J.Stairmand Trans Inst. Chem. Eng. Vol 29 pp 356-383 (1951)

10. A.J.T. Linden, Proc. The Institution of Mechanical Engineers, vol.160.pp 233-251 (1949)

11. A.Stem, K Caplan, and P. Bush, Division of Refining, American Petroleum Institute, New York, vol 67 (1955)

12. Z.Ji, Z. Xiong, X.Wu, H. Chen and H.Wu, Powder Technology, vol.191, pp. 254-259 (2009) 